\title{
ESTUdO SOBRE A ADSORÇÃO DO FLUIDO DE PERFURAÇÃO SALGADO CONTENDO POLÍMEROS SOBRE SIO,
}

\section{João C. Queiroz Neto}

Centro de Pesquisas e Desenvolvimento da Petrobras, Rio de Janeiro - RJ, Brasil

Evaristo Chalbaud Biscaia Jr.

Coordenação dos Programas de Pós-graduação de Engenharia, Programa de Engenharia Química, Universidade Federal do Rio de Janeiro, Rio de Janeiro - RJ, Brasil

Denise F. S. Petri*

Instituto de Química, Universidade de São Paulo, Av. Prof. Lineu Prestes, 748, 05508-900 São Paulo - SP, Brasil

Recebido em 6/6/06; aceito em 9/10/06; publicado na web em 28/5/07

\begin{abstract}
ADSORPTION BEHAVIOR OF POLYMER-BASED DRILLING FLUIDS ON $\mathrm{SiO}_{2}$ Polysaccharide-based drilling fluids have been often applied in horizontal wells of petroleum reservoirs in Campos, Rio de Janeiro. The present study aimed to understand the mechanism of adsorption and desorption of the drill-in fluid, xanthan, modified starch and lubricant on $\mathrm{SiO}_{2}$ by means of ellipsometry. The effect of $\mathrm{pH}$ and brine on the mean thickness (D) of adsorbed layer was systematically investigated. The adsorption was mainly favored under alkaline conditions. A model has been proposed to explain this effect. The adsorption isotherms determined separately for xanthan and starch on $\mathrm{SiO}_{2}$ surfaces could be fitted with the Langmuir model, which yielded similar adsorption constant values.
\end{abstract}

Keywords: adsorption; xanthan; starch.

\section{INTRODUÇÃO}

Os fluidos de perfuração do tipo "drill-in" foram desenvolvidos de modo a atender às condições exigidas na operação de perfuração de poços horizontais no trecho do reservatório produtor de petróleo e para o devido condicionamento do poço para produção, ao final da perfuração ${ }^{1-3}$. A perfuração ocorre normalmente através da aplicação de peso e rotação na coluna onde, na extremidade, está acoplada uma broca cortante. Simultaneamente, circula-se fluido de perfuração pelo interior do poço, de acordo com o seguinte caminho: o fluido é injetado pelo interior da coluna, passa através de jatos existentes na broca e retorna pelo espaço anular formado pela parede do poço e a coluna de perfuração. O fluido usado é cuidadosamente projetado para atender a uma série de finalidades. Deve reduzir a fricção e o desgaste das brocas, carrear os sólidos gerados na operação, controlar a pressão exercida pelos fluidos dos reservatórios perfurados, entre outras funções ${ }^{3}$.

As formulações de fluidos "drill-in" à base de água são as mais utilizadas, apresentando em sua formulação um espessante, um controlador de filtrado polimérico, um alcalinizante, sais inibidores de argilas e adensantes e um agente de tamponamento, que pode ser cloreto de sódio ou carbonato de cálcio micronizado ${ }^{4-6}$. Os polímeros mais usados nas formulações à base de água são xantana (espessante) e o amido propilado (controlador de filtrado). A xantana é um biopolímero de cadeias ramificadas, de caráter aniônico e com massa molar elevada, em torno de $2.000 .000 \mathrm{~g} / \mathrm{mol}^{7}$. Xantana é obtida pela fermentação microbiana, em condições aeróbicas, a partir de açúcares de cana ou do milho ou de seus derivados, que em presença de microorganismos da espécie Xanthomonas campestris são convertidos em uma goma solúvel no meio reacional. Depois, por meio da precipitação em um não-solvente obtém-se a xantana em pó. Por suas propriedades espessantes e estabilidade térmica até $100{ }^{\circ} \mathrm{C}$ é usada no controle da viscosidade do fluido de perfuração ${ }^{8}$. No estado sólido as

*e-mail: dfsp@usp.br cadeias de xantana adotam a conformação helicoidal. Em solução a transição de estado ordenado (hélices) para desordenado (novelos) pode ser favorecida em condições de altas temperaturas ou meio alcalino ${ }^{9}$. O amido propilado é um polissacarídeo de caráter aniônico com massa molar elevada, em torno de $2.000 .000 \mathrm{~g} / \mathrm{mol}^{10}$, constituído por amilose e amilopectina. A amilose apresenta uma cadeia linear de glicose, enquanto a amilopectina é constituída por cadeias altamente ramificadas de unidades de maltose e isomaltose. Pode ser obtido a partir de milho, batata ou mandioca, e a razão entre a amilose e a amilopectina muda com o tipo de matéria-prima e com o tempo de maturação. Por sua vez, essas variáveis influem na viscosidade e na capacidade de gelificação. $\mathrm{O}$ amido propilado, por apresentar boa estabilidade térmica, é utilizado para controlar as propriedades filtrantes nos fluidos de perfuração à base de água ${ }^{10,11}$. Em solução, as cadeias de amido podem sofrer mudança conformacional de helicoidal para enovelada quando há aumento de temperatura, $\mathrm{pH}$ ou força iônica do meio ${ }^{10}$. As estruturas helicoidais presentes em muitos polissacarídeos são devidas às fortes ligações de hidrogênio intramolecular. Estas ligações podem ser enfraquecidas quando as condições do meio são alteradas, como aumento de $\mathrm{pH}$ e temperatura. Os polissacarídeos (xantana e amido modificado) interagem com partículas sólidas inorgânicas para reforçar a torta formada e atingir as propriedades reológicas desejadas em grandes faixas de temperatura. A degradação de polímeros com aumento de temperatura é um dos fatores que afeta a termo-estabilidade dos fluídos de perfuração. A estabilidade térmica parece estar intimamente relacionada com o grau de reticulação física dos polímeros ${ }^{12,13}$, o qual depende da massa molar e do tipo de grupos funcionais presentes nos polímeros.

Os lubrificantes para fluidos de perfuração são, na maioria, misturas de monooleatos e dioleatos de polietilenoglicol. O que diferencia um lubrificante comercial de outro é a proporção entre esses produtos na formulação do lubrificante. A escolha do lubrificante é uma etapa crítica, pois a escolha inadequada deste produto resulta no aumento da fricção e do toque na coluna de perfuração, interferindo na operação de perfuração ${ }^{14}$. 
O fluido de perfuração "drill-in" salgado contendo polímeros é o mais usado nas perfurações horizontais de reservatórios de petróleo na bacia de Campos (Brasil), formados na sua maioria por areia não consolidada. Contudo, pouco se sabe sobre a adsorção desse fluido de perfuração sobre areia, ou sobre o processo de dessorção do mesmo. Neste trabalho, foram feitos estudos sistemáticos de adsorção e dessorção do fluido de perfuração "drill-in" salgado contendo polímeros, bem como da xantana, do amido propilado e do lubrificante separadamente sobre lâminas de Si através de medidas de elipsometria. Lâminas de $\mathrm{Si}$ compostas de uma camada de $\mathrm{SiO}_{2}$ nativa foram escolhidas como substratos por apresentarem composição química superficial semelhante à areia e por serem planas e refletoras, requisitos da elipsometria. Elipsometria é uma técnica óptica não destrutiva que permite determinar a espessura de filmes refletores, que varie de 0,1 até várias centenas de nanômetros ${ }^{15,16}$.

\section{PARTE EXPERIMENTAL}

Para os ensaios de adsorção e de dessorção utilizaram-se como substratos lâminas de $\mathrm{Si}$, com camada nativa de $\mathrm{SiO}_{2}$ de aproximadamente $2 \mathrm{~nm}$ (Quest, USA). As lâminas de Si foram primeiramente limpas em uma mistura oxidativa contendo $\mathrm{H}_{2} \mathrm{O}_{2}(30 \% \mathrm{em}$ volume), $\mathrm{NH}_{4} \mathrm{OH}$ (30\% em volume de $\mathrm{NH}_{3}$ ) e $\mathrm{H}_{2} \mathrm{O}$, na proporção de 1:1:4 em volume, à temperatura de $75^{\circ} \mathrm{C}$, durante $20 \mathrm{~min}^{17}$. Depois deste período as lâminas foram retiradas da mistura, lavadas em água destilada e secas com jatos de $\mathrm{N}_{2}$. As lâminas foram então caracterizadas por elipsometria.

A fim de se verificar o efeito do $\mathrm{pH}$ na adsorção do fluido "drill-in" salgado sobre lâminas de $\mathrm{Si} / \mathrm{SiO}_{2}$, os fluidos foram preparados em $\mathrm{pH} 4,7$ ou 10. Os pHs 4 e 10 foram ajustados pela adição de $\mathrm{HCl}$ e $\mathrm{NaOH}$, respectivamente. A Tabela 1 apresenta a formulação do fluido "drill-in" salgado, as propriedades e a função

Tabela 1. Formulação (para $1 \mathrm{~L}$ ), propriedades e função dos componentes do fluido de perfuração "drill-in" salgado

\begin{tabular}{lc}
\hline PRODUTO & CONCENTRAÇÃO \\
\hline Água destilada & QSP \\
Xantana & $4,28 \mathrm{~g}$ \\
Amido propilado & $22,86 \mathrm{~g}$ \\
Óxido de magnésio & $5,71 \mathrm{~g}$ \\
NaCl PAA & $40,57 \mathrm{~g}$ \\
Antiespumante & $0,5 \mathrm{~cm}^{3}$ \\
Bactericida & $0,7 \mathrm{~cm}^{3}$ \\
Carbonato de cálcio & $100,00 \mathrm{~g}$ \\
\hline PROPRIEDADES & VALORES \\
\hline Densidade, g/cm ${ }^{3}$ & 1,21 \\
Viscosidade aparente, mPa.s & 33,0 \\
Viscosidade plástica, mPa.s & 21,0 \\
Limite de escoamento, KPa & 115,0 \\
GI'/GF, KPa & $14 / 33$ \\
pH & 9,4 \\
Filtrado API, cm ${ }^{3}$ & 3,40 \\
\hline PRODUTO & FUNÇÃO \\
\hline Xantana & Espessante \\
Amido propilado & Controlador do filtrado \\
Óxido de magnésio & Controlador do pH do fluido \\
Antiespumante & Evita excesso de espuma no fluido \\
Bactericida & Evita fermentação do fluido \\
Salmoura de NaCl & Adensante e inibidor de argilas \\
Carbonato de cálcio & Agente de tamponamento e adensante \\
\hline
\end{tabular}

de cada um de seus componentes. Para os ensaios de adsorção, lâminas de $\mathrm{Si} / \mathrm{SiO} 2$ previamente limpas e caracterizadas foram imersas no fluido de perfuração por $72 \mathrm{~h}$ a $70 \pm 2{ }^{\circ} \mathrm{C}$, para mimetizar as condições dos poços horizontais na bacia de Campos. Depois deste período foram retiradas, lavadas com água destilada e secas sob jatos de $\mathrm{N}_{2}$. As espessuras das camadas adsorvidas foram então caracterizadas por elipsometria.

Soluções de xantana, amido propilado ou lubrificante foram preparadas na faixa de concentração de 0,0001 a 2,0 g/L, em pH 3, 6 e 12 . Os ensaios de adsorção foram realizados a $70 \pm 2{ }^{\circ} \mathrm{C}$, fixando-se o tempo de interação em $72 \mathrm{~h}$.

Outra série de experimentos de adsorção de xantana e amido propilado sobre lâminas de $\mathrm{Si} / \mathrm{SiO} 2$ foi feita a partir de soluções preparadas na faixa de concentração de 0,0001 a $1,0 \mathrm{~g} / \mathrm{L}$, em pH 6 e concentração de $\mathrm{NaCl}$ variando de 5000 a $50000 \mathrm{ppm}$, a $70 \pm 2$ ${ }^{\circ} \mathrm{C}$, fixando-se o tempo de interação em $2 \mathrm{~h}$.

Os ensaios de dessorção foram realizados a $70 \pm 2{ }^{\circ} \mathrm{C}$, em tempo de imersão curto $(1 \mathrm{~h})$ e longo (2 dias) em $\mathrm{HCl} 1,0 \mathrm{~mol} / \mathrm{L}(\mathrm{pH}$ $0)$. Depois do período de dessorção as amostras foram retiradas, lavadas com água destilada e secas sob jatos de $\mathrm{N}_{2}$. As espessuras dos filmes remanescentes secos foram determinadas por elipsometria.

\section{Elipsometria}

A elipsometria ${ }^{15,16}$ consiste em medir a mudança do estado de polarização da luz após a reflexão, a partir de uma superfície isotrópica refletora. As mudanças de fase $(\Delta)$ e de amplitude $(\psi)$ da radiação após a reflexão são medidas com relação à radiação incidente. $\Delta$ e $\psi$ dependem do comprimento de onda da radiação $(\lambda)$, do ângulo de incidência $(\phi)$, da espessura (D) e do índice de refração (n) de um filme isotrópico e refletor, como mostra a equação fundamental da elipsometria ${ }^{15}$ (Equação 1)

$\tan \psi \mathrm{e}^{\mathrm{i} \Delta}=\mathrm{f}(\mathrm{n}, \mathrm{D}, \phi \mathrm{e} \lambda)$

Através da Equação 1, das relações de Drude e Fresnel, de cálculos interativos e matrizes de Jones ${ }^{15}$ pode-se obter $\mathrm{n}$ e D independentemente. Quando as espessuras das camadas são muito finas $(\approx 1 \mathrm{~nm})$ ou quando o contraste óptico não é suficiente para que $\mathrm{D}$ e $\mathrm{n}$ sejam obtidos independentemente um do outro, então, usa-se o índice de refração fixo a partir de dados da literatura ou do fabricante, e determina-se a espessura do filme (D). Usou-se os seguintes índices de refração: $\mathrm{Si}: \mathrm{n}=3.858-0.018 \mathrm{i}^{18} ; \mathrm{SiO}_{2}: \mathrm{n}=1,462^{18}$; xantana ou amido ou lubrificante: $\mathrm{n}=1,500^{19}$, ar $=1,00$. As medidas elipsométricas foram realizadas em elipsômetro DRE-ELX02 (Ratzeburg, Alemanha) equipado com um laser $\mathrm{He}-\mathrm{Ne}$ $(\lambda=632,8 \mathrm{~nm})$, com ângulo de incidência ajustado em $70^{\circ}$, onde a cada 4 s valores de $\Delta$ e $\psi$ foram automaticamente registrados. $\mathrm{O}$ software utilizado para realizar os cálculos iterativos acompanha o elipsômetro DRE-ELX02.

Os ensaios de adsorção com fluido "drill-in" salgado ou com soluções de polímeros ou lubrificante sobre lâminas de $\mathrm{Si} / \mathrm{SiO}_{2}$ em larga faixa de $\mathrm{pH}$ foram realizados ex-situ por limitações experimentais: observou-se forte espalhamento resultante da interação do laser com o meio; as condições de $\mathrm{pH}$ alcalino provocariam danos à cela elipsométrica e, a cela elipsométrica disponível não pode ser termostatizada a $70 \pm 2{ }^{\circ} \mathrm{C}$.

\section{Planejamento Fatorial}

Para identificar os fatores mais influentes na adsorção dos polímeros e no lubrificante (da formulação "drill-in") sobre as lâ- 
minas de $\mathrm{Si} / \mathrm{SiO}_{2}$ foi utilizado um planejamento fatorial do tipo "Plackett-Burman". A análise estatística foi feita no programa Statistica versão 7.0. Este tipo de planejamento permite identificar os fatores mais influentes nas diferentes respostas de interesse a partir dos valores dos efeitos obtidos no planejamento, usando um número reduzido de experimentos ${ }^{20}$. As variáveis usadas como fatores foram salinidade (concentração de $\mathrm{NaCl}$ ), $\mathrm{pH}$, temperatura e as concentrações de xantana, amido propilado, lubrificante e surfatante não iônico. Como resposta foi usada a variável espessura da camada adsorvida (D). Na Tabela 2 são apresentados os níveis dos fatores usados nesse planejamento fatorial.

Tabela 2. Valores dos níveis para os 7 fatores utilizados no planejamento fatorial tipo Plackett-Burman

\begin{tabular}{lccc}
\hline Fatores & \multicolumn{3}{c}{ Níveis } \\
& -1 & 0 & +1 \\
\hline Conc. amido propilado, ppm & 1000 & 1500 & 2000 \\
Conc. goma xantana, ppm & 500 & 750 & 1000 \\
Conc. lubrificante, v/v \% & 1,0 & 1,5 & 2,0 \\
Salinidade $(\mathrm{NaCl}), \mathrm{ppm}$ & 0,0 & 40000 & 80000 \\
Conc. surfatante, ppm & 1250 & 1875 & 2500 \\
pH & 3 & 7,5 & 12 \\
Temperatura, ${ }^{\circ} \mathrm{C}$ & 30 & 50 & 70 \\
\hline
\end{tabular}

\section{RESULTADOS E DISCUSSÃO}

Ensaios exploratórios de adsorção e dessorção do fluido "drillin" salgado contendo polímeros sobre lâminas de $\mathrm{Si} / \mathrm{SiO}_{2}$

Nos ensaios de adsorção do fluido "drill-in" salgado contendo polímeros sobre lâminas de $\mathrm{Si} / \mathrm{SiO} 2$ utilizou-se a temperatura média de fundo de poço na bacia de Campos e meios ácido, neutro e básico. As espessuras médias dos filmes adsorvidos (D) estão apresentadas na Figura 1. É interessante observar que as maiores espessuras foram obtidas em pH 4 (109 \pm 12 nm), ou seja, em meio ácido. Os valores de D obtidos em pH $7(68 \pm 20 \mathrm{~nm})$ e $\mathrm{pH} 10(66 \pm 6 \mathrm{~nm})$ foram muito semelhantes. Após as medições da espessura da camada adsorvida, as amostras foram imersas em $\mathrm{HCl}(\mathrm{pH} 1)$ por $12 \mathrm{~h}$ para se avaliar a dessorção em meio ácido. Em seguida foram retiradas, lavadas em água destilada, secas com jato de $\mathrm{N}_{2}$ e novamente medidas por elipsometria. As espessuras médias obtidas estão apresentadas na Figura 1. Considerando-se os desvios médios, todas as espessuras diminuíram até um valor aproximadamente constante de $\sim 40 \mathrm{~nm}$, independentemente do $\mathrm{pH}$ em que foram preparados os fluidos. A dessorção mais acentuada ocorreu nas amostras do fluido preparado com $\mathrm{pH} 4$, enquanto que em pH 10 a dessorção foi menos acentuada.

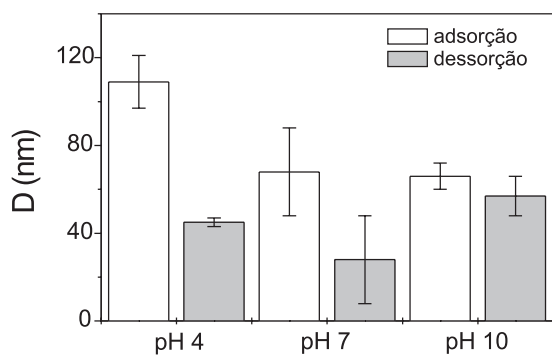

Figura 1. Espessuras médias $(D)$ dos filmes do fluido salgado contendo polímero: colunas brancas correspondem à adsorção sobre lâminas de sílica durante $72 h$ a $70 \pm 2{ }^{\circ} \mathrm{C}$, de fluidos preparados em $\mathrm{pH} 4,7$ e 10; colunas cinzas correspondem às espessuras após dessorção durante $12 \mathrm{~h}$, em pH 1 e $70 \pm 2{ }^{\circ} \mathrm{C}$
As espessuras médias dos filmes adsorvidos são altas e correspondem a multicamadas ou estruturas agregadas adsorvidas sobre as lâminas. Os fluidos "drill-in" salgados preparados em $\mathrm{pH}$ 4, 7 e 10 são dispersões com aspecto fortemente turvo. A alta massa molar e a estrutura ramificada da xantana e amido propilado favorecem a agregação. $\mathrm{O}$ estudo de adsorção do fluido salgado de perfuração sobre superfície de sílica em função do $\mathrm{pH}$ mostrou que a adsorção da mistura é favorecida em meio ácido e que a dessorção em meio ácido foi mais pronunciada justamente nas camadas mais espessas, obtidas em meio ácido. Com base nestas conclusões surgiram os seguintes questionamentos: qual é o papel do $\mathrm{pH}$ do meio na adsorção/dessorção de cada polímero? Existe competição entre os polímeros pela superfície de sílica? Existe efeito sinergético entre eles durante o processo de adsorção do fluido? Séries de experimentos foram realizadas para responder a estas perguntas.

Efeito do pH sobre a adsorção de xantana, de amido propilado ou do lubrificante sobre lâminas de $\mathrm{Si} / \mathrm{SiO}_{2}$

O efeito do $\mathrm{pH}$ sobre a espessura média da camada de xantana, de amido propilado ou do lubrificante sobre lâminas de $\mathrm{Si} / \mathrm{SiO}_{2}$ em função da concentração de adsorbato está apresentado nas Figuras $2 \mathrm{a}, 2 \mathrm{~b}$ e $2 \mathrm{c}$, respectivamente. A faixa de concentração investigada está bem abaixo daquela usada na formulação, por causa da dificuldade em solubilizar os polissacarídeos. Observações gerais são que a xantana formou filmes mais espessos sobre as lâminas de silício que o amido propilado e que a adsorção dos três adsorbatos é fortemente favorecida em $\mathrm{pH} 12$.

$\mathrm{O}$ ponto isoelétrico da sílica ${ }^{21,22}$ está próximo do $\mathrm{pH}$ 3. Em $\mathrm{pH} 3$ (círculo cheio), a adsorção da xantana e do amido propilado pode ser favorecida por ligações de $\mathrm{H}$, uma vez que a superfície da sílica apresenta grupos silanóis pouco dissociados e ambos os polissacarídeos são ricos em grupos hidroxilas e ácidos carboxílicos, no caso da xantana. Da mesma forma, moléculas do lubrificante ricas em hidroxilas podem interagir com o substrato. Neste $\mathrm{pH}$ as espessuras médias das camadas adsorvidas de xantana e lubrificante são da ordem de 1,0 nm, enquanto a de amido chegou a $\sim 6,0 \mathrm{~nm}$. No outro extremo, em pH 12, tanto os grupos silanóis como as hidroxilas ou os ácidos carboxílicos estão desprotonados. Nesta situação seria esperado que a forte repulsão eletrostática reduzisse a espessura da camada adsorvida. Entretanto, as observações experimentais mostram exatamente o comportamento oposto, ou seja, as camadas atingem espessuras máximas entre 60 e $80 \mathrm{~nm}$ para amido e xantana, respectivamente, em concentrações de até 1,0 g/L. O amido é composto por cadeias lineares de amilose e cadeias ramificadas de amilopectina, enquanto a xantana apresenta cadeias laterais de manose e ácido glucurônico. Especialmente o entrelaçamento de cadeias laterais pode ser favorecido com o aumento da concentração, aumentando assim a agregação em solução e disponibilizando uma quantidade menor de cadeias livres para adsorver. Experimentalmente, observou-se o aumento de turbidez das soluções de xantana e amido com o aumento de concentração. Além disso, independente da concentração, em $\mathrm{pH}$ alcalino ocorre a transição estrutural das cadeias de xantana ${ }^{9}$ e amido ${ }^{10}$ em solução passando de conformação helicoidal para enovelada. Estas mudanças conformacionais das cadeias poliméricas podem explicar o aumento da espessura da camada adsorvida com o aumento do $\mathrm{pH}$ para situações em que a concentração de polímero era de até $1,0 \mathrm{~g} / \mathrm{L}$. Cadeias enoveladas apresentam maior flexibilidade para interagir com cadeias vizinhas (tanto em solução como na superfície) que cadeias rígidas helicoidais, aumentando a quantidade de material adsorvido.

As isotermas de adsorção de xantana e de amido sobre lâminas de $\mathrm{Si}$, em pH 6 na faixa de concentração de $1,0 \times 10^{-4}$ até $1,0 \mathrm{~g} / \mathrm{L}$ (Figuras 2a e 2b) mostram o aumento dos valores de D com o au- 
mento da concentração até atingir um patamar, ao qual se atribuiu o valor de $\mathrm{D}_{\max }$. Nestas condições, os valores médios de $\mathrm{D}_{\max }$ observados para xantana e amido foram $1,0 \pm 0,1$ e $0,8 \pm 0,2 \mathrm{~nm}$, respectivamente. Considerando que Wiegand e colaboradores ${ }^{23}$ estimaram a espessura média de uma monocamada de polissacarídeo como sendo $0,7 \mathrm{~nm}$, os valores de $\mathrm{D}_{\max }$ encontrados caracterizam a adsorção de monocamada de xantana e amido. Portanto, o valor de $\mathrm{D}_{\max }$ corresponde à espessura da monocamada na situação de equilíbrio de adsorção. Quando as lâminas de Si cobertas por xantana ou amido são imersas em água por $1 \mathrm{~h}$ observa-se dessorção de até $30 \%$ do material adsorvido, indicando que a adsorção é reversível. A observação experimental da adsorção reversível de xantana ou amido sobre lâminas de Si na forma de monocamadas permite usar o modelo de adsorção de Langmuir para ajustar as isotermas ${ }^{24}$. O grau de recobrimento $\theta$ foi calculado dividindo-se a espessura D medida em uma dada concentração de polímero pela espessura no limite da adsorção $\mathrm{D}_{\max }{ }^{25,26}$ :

$\theta=\frac{\mathrm{D}}{\mathrm{D}_{\max }}$
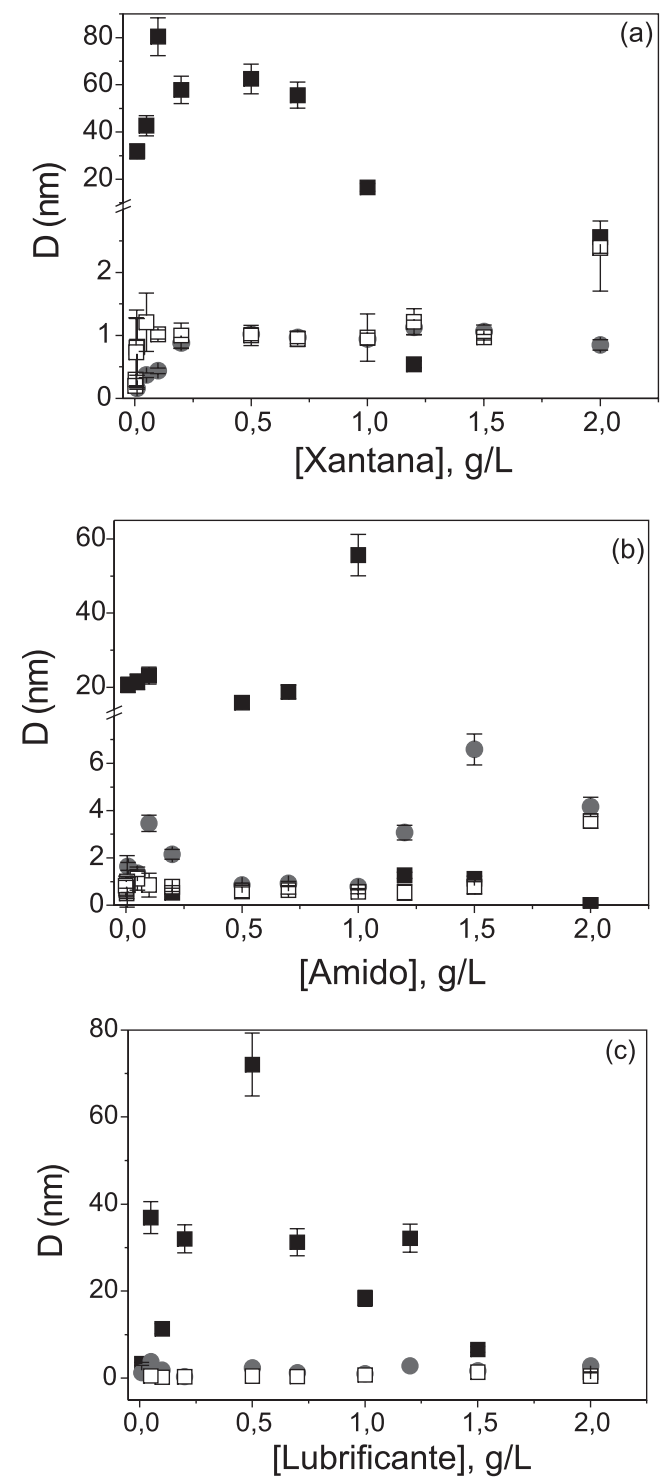

Figura 2. Valores de espessura D em função da concentração de (a) xantana, (b) amido propilado e (c) lubrificante, adsorvidos sobre lâminas de $\mathrm{Si} / \mathrm{SiO}{ }_{2}$ em pH 3 (círculo cheio), pH 6 (quadrado vazio) e pH 12 (quadrado cheio)
A dependência de $\theta$ com a concentração de polímero pôde ser ajustada pelo modelo de adsorção de Langmuir:

$\theta=\frac{K_{\text {ads }} \cdot C_{\text {polimero }}}{\left(1+K_{\text {ads }} \cdot C_{\text {polimero }}\right)}$

onde $\mathrm{K}_{\text {ads }}$ é a constante de adsorção e $\mathrm{C}_{\text {polímero }}$ é a concentração de polímero. Quanto maior for o valor de $\mathrm{K}_{\text {ads }}$, maior é a afinidade entre substrato e adsorbato.

As Figuras $3 \mathrm{a}$ e $3 \mathrm{~b}$ mostram o grau de recobrimento $\theta$ em função da concentração de xantana e amido, respectivamente, juntamente com os melhores ajustes obtidos. Os valores das constantes de adsorção $\mathrm{K}_{\mathrm{ads}}$ obtidos para a xantana e o amido propilado a partir dos ajustes foram 455 e $355 \mathrm{~L} / \mathrm{g}$, respectivamente, indicando que xantana e amido têm afinidades semelhantes pela lâmina de sílica. Porém, não se conseguiu ajuste satisfatório para as isotermas do lubrificante. Os valores de $\mathrm{K}_{\mathrm{ads}}$ de 455 e $355 \mathrm{~L} / \mathrm{g}$ podem ser multiplicados pela massa molar média da xantana e amido $(2.000 .000 \mathrm{~g} / \mathrm{mol})$, obtendo-se os valores de $910 \times 10^{6}$ e $710 \times 10^{6}$ $\mathrm{L} / \mathrm{mol}$, respectivamente. Estes valores indicam alta afinidade dos polissacarídeos pelas superfícies de $\mathrm{Si} / \mathrm{SiO}_{2}$.
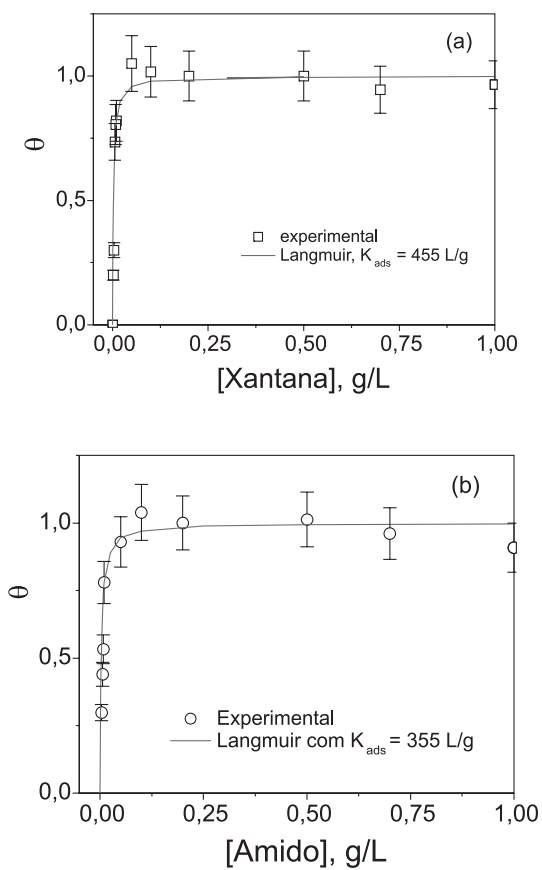

Figura 3. Grau de recobrimento $\theta$ em função da concentração de (a) xantana $e$ (b) amido, juntamente com os respectivos ajustes (linha), seguindo o modelo de Langmuir

Dessorção em meio ácido de xantana, amido propilado ou lubrificante imobilizados sobre lâminas de $\mathrm{Si} / \mathrm{SiO}_{2}$

Os ensaios de dessorção em pH 0 foram realizados para estudar separadamente a dessorção da goma xantana, do amido propilado e do lubrificante na superfície da sílica e com isso se entender o comportamento da dessorção do fluido salgado com polímeros na sílica. Foram escolhidos um tempo curto de imersão (1 h) e um tempo longo (2 dias) de imersão em $\mathrm{HCl}$ 1,0 mol/L. Na industria do petróleo normalmente se faz a remoção da torta interna com ácido $\mathrm{HCl}$ a $12 \%$ p/p ( 3,0 mol/L), que é um meio fortemente ácido. As Figuras 4a, 4b e 4c apresentam as espessuras das camadas, antes e após a dessorção em $\mathrm{HCl}$, para xantana, amido propilado e lubrificante, respectivamente, em função da concen- 
tração de adsorbato. Verifica-se que a dessorção dos três adsorbatos foi mais pronunciada quando o tempo de imersão se estendeu até 2 dias, chegando a reduzir em até $50 \%$ os valores iniciais de D. Entretanto, o meio ácido não foi capaz de remover totalmente a camada adsorvida, corroborando com os altos valores de $\mathrm{K}_{\text {ads }}$ estimados nas Figuras 3a e 3b.
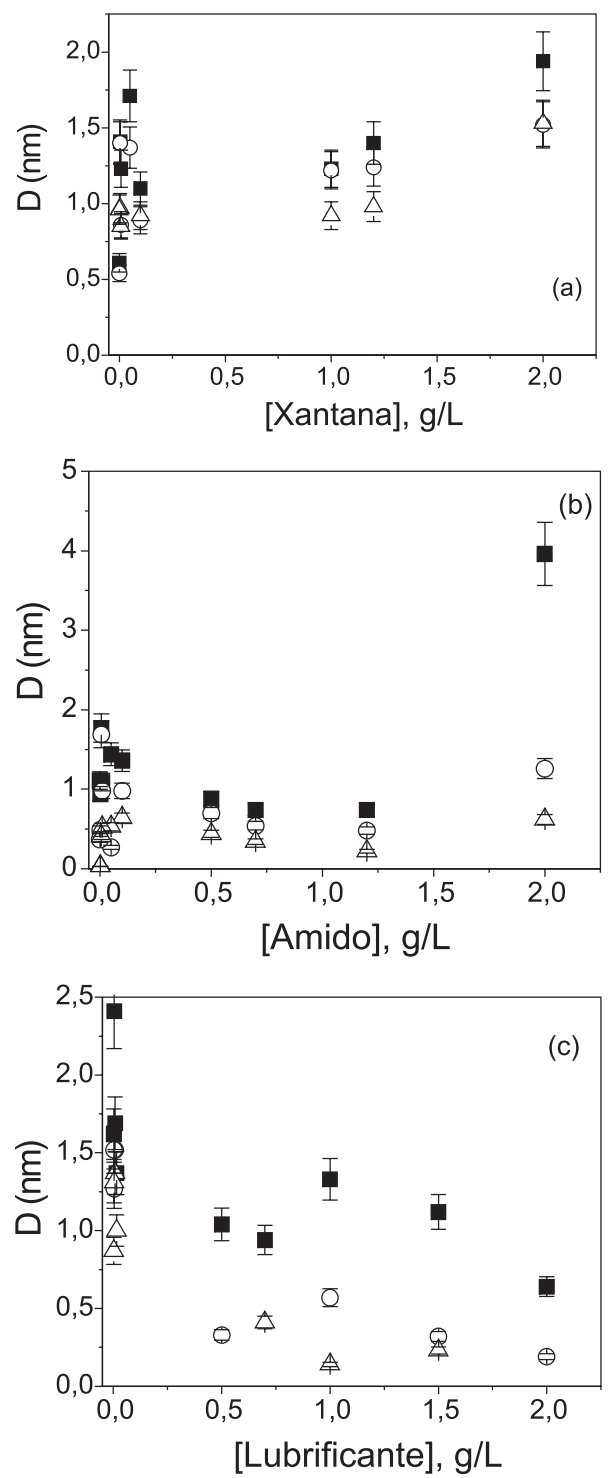

Figura 4. Espessura média D dos filmes adsorvidos (quadrado cheio) $e$ remanescentes após a imersão em $\mathrm{HCl}$ 1,0 M durante 1 h (círculo vazio) e 2 dias (triângulo vazio) determinados em função da concentração de xantana (a), amido propilado (b) e lubrificante (c)

Efeito da concentração de $\mathrm{NaCl}$ sobre a adsorção de xantana e de amido propilado sobre lâminas de $\mathrm{Si} / \mathrm{SiO}_{2}$

A formulação do fluido "drill-in" contém 40000 ppm de $\mathrm{NaCl}$ (Tabela 1). Nesta série de experimentos de adsorção, as soluções dos polissacarídeos foram preparadas na faixa de concentração de $\mathrm{NaCl}$ de 5000 a 50000 ppm, a fim de se estudar o efeito do $\mathrm{NaCl}$ sobre a adsorção dos polissacarídeos sobre lâminas de $\mathrm{Si} / \mathrm{SiO}_{2}$. A espessura média $\mathrm{D}$ dos filmes de xantana e amido propilado sobre lâminas de $\mathrm{Si} / \mathrm{SiO}_{2}$, em 5000 ppm NaCl (asterisco), 15000 ppm $\mathrm{NaCl}$ (triângulo vazio), 35000 ppm NaCl (círculo vazio) e 50000 ppm (quadrado cheio), está apresentada nas Figuras 5a e 5b. O pH do meio e o tempo de adsorção foram mantidos constantes em $\mathrm{pH}$ 6 e 2 h. No caso da xantana (Figura 5a), praticamente não há efeito da concentração de $\mathrm{NaCl}$ sobre os valores médios de D. Nasr-ElDin e Taylor ${ }^{9}$ verificaram que a viscosidade de soluções aquosas de xantana $(2,0 \mathrm{~g} / \mathrm{L})$ em pH neutro não sofre efeito de cátions monovalentes, evidenciando que a conformação e solvação das cadeias em solução não são alteradas substancialmente com o aumento da concentração de cátions $\mathrm{Na}^{+}$. Este comportamento em solução também foi verificado pelo grupo de Rinaudo ${ }^{27}$ e explicado com base no grande tamanho de persistência $(\sim 45 \mathrm{~nm})$ das cadeias de xantana na conformação helicoidal. Esta propriedade em solução pode explicar os resultados da Figura 5a, pois se as características estruturais das cadeias em solução estão sendo mantidas, as características das camadas adsorvidas também se mantêm, independentemente da força iônica do meio.
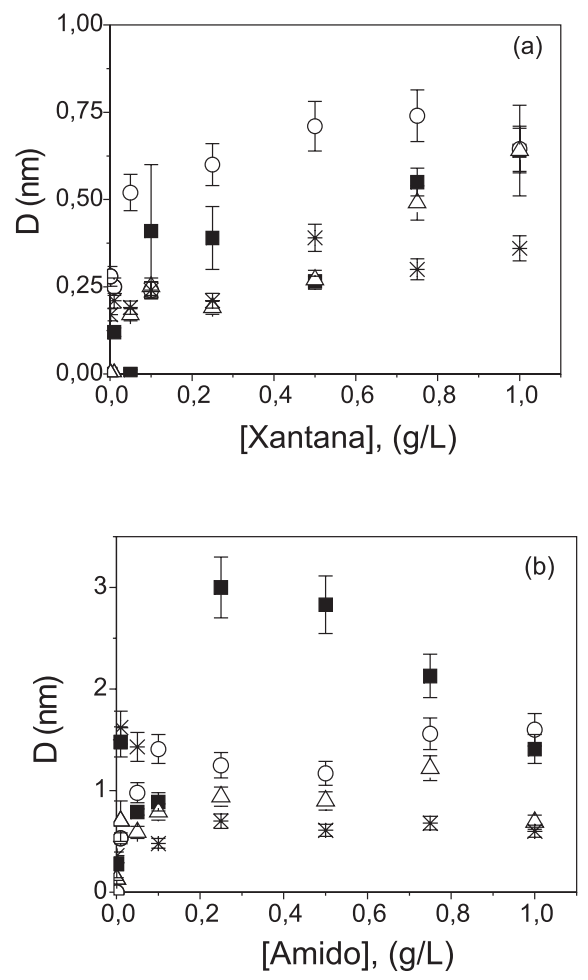

Figura 5. Espessura média $D$ em função da concentração de xantana (a) $e$ amido propilado (b) adsorvidos sobre lâminas de $\mathrm{Si} / \mathrm{SiO}_{2}$ em $5000 \mathrm{ppm} \mathrm{NaCl}$ (asterisco), $15000 \mathrm{ppm} \mathrm{NaCl}$ (triângulo vazio), $35000 \mathrm{ppm} \mathrm{NaCl}$ (círculo vazio) e 50000 ppm (quadrado cheio). $\mathrm{O}$ pH do meio e tempo de adsorção foram mantidos constantes em $\mathrm{pH} 6$ e $2 \mathrm{~h}$

No caso do amido, o aumento da concentração de $\mathrm{NaCl}$ levou a valores maiores de D. Este tipo de comportamento é observado para adsorção de polieletrólitos com alta densidade de carga sobre superfícies sólidas ${ }^{28,29}$. A idéia é que a alta concentração de sal blinda as cargas dos segmentos do polieletrólito, diminuindo a repulsão entre os mesmos. Consequientemente, as cadeias se comportam como polímeros não-carregados, assumindo conformações do tipo alça e cauda e aumentando a quantidade de material adsorvido. Este tipo de situação é favorecida somente quando as interações entre substrato e adsorbato não são de natureza eletrostática. Há alguns trabalhos na literatura $^{30,31}$ que mostram o efeito da força iônica no processo de gelificação de amido. Observou-se que a variação de entalpia de gelificação diminuiu com o aumento da concentração de $\mathrm{NaCl}^{31}$. Semelhantemente ao efeito do aumento do $\mathrm{pH}$, este efeito foi expli- 
cado através da transição de ordem (hélice)-desordem (novelo) provocada pela presença do sal o qual, além de alterar as conformações das cadeias, impede as interações polímero-polímero e favorece as interações polímero-água, resultando na diminuição de entalpia para as regiões organizadas. $\mathrm{O}$ aumento de $\mathrm{D}$ de amido com a concentração de sal pode ser devido às mudanças conformacionais da cadeia principal e de suas ramificações (amilopectina), que são mais longas que as ramificações da xantana. Desta forma, o aumento da força iônica favoreceu a relaxação das estruturas das cadeias de amido em solução, promovendo a formação de camadas de amido mais espessas, como observado na Figura $5 b$.

\section{Identificação dos fatores que governam a adsorção dos aditivos do fluido salgado contendo polímeros sobre sílica}

Segundo a literatura ${ }^{32,33}$, de forma geral, os fatores que governam a adsorção de polímeros em superfícies de sílica são $\mathrm{pH}$, os valores das cargas do adsorbato e do adsorvente, as concentrações e massas molares dos polímeros, a temperatura, a salinidade e a presença de surfactantes não-iônicos. Por isso, foi feito um estudo de identificação dos fatores mais influentes nesse processo usando os parâmetros sugeridos na literatura ${ }^{32,33}$, através de um planejamento fatorial do tipo Plackett-Burman ${ }^{20}$, com 7 fatores. Nesse estudo consideraram-se os valores de massa molar da xantana ${ }^{7}$ e do amido propilado $^{10}$ iguais a $2.000 .000 \mathrm{~g} / \mathrm{mol}$. Na Tabela 3 podem ser vistos os resultados da variável de resposta (D).

Pelo gráfico de Pareto na Figura 6 verifica-se que o efeito para a variável $\mathrm{pH}$ se destaca em relação aos demais efeitos, indicando que o pH é quem rege o processo de adsorção desses polímeros e do fluido de perfuração na sílica. Como discutido anteriormente, o aumento do $\mathrm{pH}$ provoca transição conformacional das cadeias de amido e xantana de helicoidal para enolevada. Estados conformacionais desordenados em solução favorecem a adsorção, aumentando a espessura da camada adsorvida. Outra observação interessante é que os efeitos de xantana e amido são semelhantes, corroborando com os valores semelhantes de $\mathrm{K}_{\text {ads }}$ obtidos a partir do ajuste pelo modelo de Langmuir (Figura 3) para adsorção de amido e xantana sobre lâminas de $\mathrm{Si} / \mathrm{SiO}_{2}$.

Experimentalmente ${ }^{34,35}$ observa-se que em um processo de adsorção competitiva entre polímeros de elevadas massas molares por um dado substrato, o polímero de maior massa molar tem a preferência. A razão para isto é que quando as cadeias mais curtas estão livres em solução, há um ganho entrópico do sistema como um todo muito maior que se as cadeias mais longas estiverem livres em solução. No sistema investigado, ambos os polissacarídeos apresentam massa molar em torno de $2.000 .000 \mathrm{~g} / \mathrm{mol}$, explicando os valores semelhantes de $\mathrm{K}_{\text {ads }}$ (Figura 3 ) e os efeitos obtidos a partir do fatorial Plackett-Burman (Figura 6).

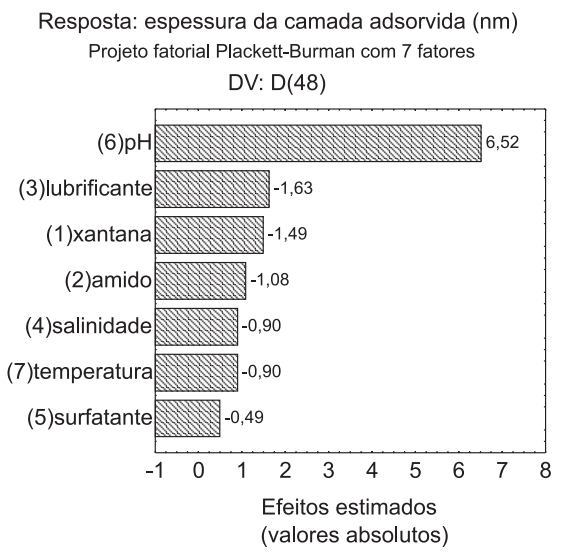

Figura 6. Gráfico de Pareto com efeitos principais e de segunda ordem: espessura da camada adsorvida $D$

Os resultados apresentados nas Figuras 2a, b e c indicam que a condição de $\mathrm{pH}$ alto leva a grandes valores de espessura das camadas formadas, independente do adsorbato ser xantana, ou amido propilado ou lubrificante. Visualmente em $\mathrm{pH}$ alto e altas concentrações ([polímero] > 2,0 g/L) de adsorbato, as soluções são sempre turvas, sinalizando que não há dissolução completa ou que há formação de agregados. Estes agregados podem adsorver no substrato, levando à formação de camadas muito espessas. As moléculas desses agregados estão fortemente ligadas entre si por pontes de hidrogênio, formando uma estrutura com aspecto de gel $^{36}$. Por outro lado, a adsorção de polissacarídeos sobre substratos ácidos é desfavorecida em $\mathrm{pH}$ alto pois, nestas condições, interações do tipo ácido-base estão ausentes ${ }^{36}$. Somente em meio neutro ou ácido as interações do tipo ácido-base podem contribuir para o processo de adsorção. Portanto, provavelmente as camadas espessas observadas em $\mathrm{pH}$ alto são resultantes da adsorção de agregados ou grandes emaranhados formados pelas cadeias enoveladas de amido ou xantana.

Efeito da concentração de íons $\mathrm{Ca}^{2+}$ sobre a adsorção de
xantana e de amido propilado sobre lâminas de $\mathrm{Si} / \mathrm{SiO}$

A formulação do fluido "drill-in" contém $100 \mathrm{~g} / \mathrm{L}$ ou aproximadamente 1,0 mol/L de íons $\mathrm{Ca}^{2+}$ (Tabela 1 ), os quais têm as funções de agente de tamponamento e adensante. Soluções de xantana e amido preparadas na presença de íons $\mathrm{Ca}^{2+}$ na faixa de concentração de 0,01 e 1,0 mol/L em pH 6 ou pH 12 formaram agregados enormes na solução, impossibilitando ensaios de adsorção.

Polímeros aniônicos em suspensão em salmouras de $\mathrm{NaCl}$ adsorvem sobre superfícies carregadas com cargas negativas quando nessa suspensão estiverem presentes íons divalentes, tais como o

Tabela 3. Matriz do planejamento fatorial Plackett-Burman usado para identificar os fatores mais influentes na adsorção do fluido salgado com polímero na superfície da sílica e as respectivas espessuras médias D obtidas após 96 h de adsorção

\begin{tabular}{|c|c|c|c|c|c|c|c|c|}
\hline Formulação & $\begin{array}{c}\text { Conc. } \\
\text { Goma xantana }\end{array}$ & $\begin{array}{c}\text { Conc. } \\
\text { amido propilado }\end{array}$ & $\begin{array}{l}\text { Conc. } \\
\text { lubrificante }\end{array}$ & Salinidade & Surfactante & $\mathrm{pH}$ & Temp. & $\mathrm{D}(\mathrm{nm}) 96 \mathrm{~h}$ \\
\hline 1 & $-1,00$ & $-1,00$ & $-1,00$ & 1,00000 & 1,00 & 1,0 & $-1,0$ & $9 \pm 2$ \\
\hline 2 & 1,00 & $-1,00$ & $-1,00$ & $-1,00$ & $-1,00$ & 1,0 & 1,0 & $8 \pm 1$ \\
\hline 3 & $-1,00$ & 1,00 & $-1,00$ & $-1,00$ & 1,00 & $-1,0$ & 1,0 & $1,4 \pm 0,6$ \\
\hline 4 & 1,00 & 1,00 & $-1,00$ & 1,00 & $-1,00$ & $-1,0$ & $-1,0$ & $0,4 \pm 0,2$ \\
\hline 5 & $-1,00$ & $-1,00$ & 1,00 & 1,00 & $-1,00$ & $-1,0$ & 1,0 & $0,45 \pm 0,05$ \\
\hline 6 & 1,00 & $-1,00$ & 1,00 & $-1,00$ & 1,00 & $-1,0$ & $-1,0$ & $0,26 \pm 0,05$ \\
\hline 7 & $-1,00$ & 1,00 & 1,00 & $-1,00$ & $-1,00$ & 1,0 & $-1,0$ & $7,7 \pm 0,8$ \\
\hline 8 & 1,00 & 1,00 & 1,00 & 1,00 & 1,00 & 1,0 & 1,0 & $3,9 \pm 0,4$ \\
\hline
\end{tabular}


$\mathrm{Ca}^{2+37}$. Deve-se ressaltar que em meio alcalino as cadeias de xantana e amido assumem conformação enovelada, como discutido anteriormente. No modelo proposto por Chiappa e colaboradores ${ }^{37}$, os cátions $\mathrm{Ca}^{2+}$ fazem a coordenação ou "bridging" entre as cargas negativas da superfície da sílica e as cargas negativas dos polímeros. Após a adsorção da primeira camada de polímero coordenada pelos íons $\mathrm{Ca}^{2+}$, as próximas camadas podem ser formadas de forma semelhante, onde os íons $\mathrm{Ca}^{2+}$ coordenariam duas cadeias de polímeros negativamente carregados. Assim, camadas espessas de fluido salgado contendo polímeros podem ser formadas sobre sílica. Uma outra possibilidade seria a adsorção de agregados de polímeros já formados em solução através da coordenação dos íons $\mathrm{Ca}^{2+}$, que adsorveriam sobre o substrato. Esta última situação parece predominar no processo de adsorção do fluido de perfuração "drill-in" sobre $\mathrm{SiO}_{2}$ (Figura 1). Dessa forma, o mecanismo pela remoção ou deslocamento da torta adsorvida nas paredes dos poros apresenta pouca tendência de ocorrer, em relação ao mecanismo de escoamento através de dutos no interior da torta. Como discutido anteriormente, a camada de fluido adsorvido é formada por agregados de polímeros, ligados por pontes de hidrogênio, que configura uma força de coesão baixa, em relação às forças iônicas que ocorrem na interface sílica-polímero. Por isso, o mecanismo de rompimento mais provável de ocorrer é o tipo de formação de dutos no interior da torta. Porém, existe condição onde o deslocamento da torta tem maior chance de ocorrer, que é quando o teor de sólidos inertes no fluido é muito grande; neste caso, ocorre uma redução na oferta de polímeros para adsorver a superfície e, com isso, esse tipo de rompimento pode ocorrer.

\section{CONCLUSÕES}

O fator mais influente na adsorção do fluido "drill-in" salgado com polissacarídeos sobre $\mathrm{SiO}_{2}$ é o $\mathrm{pH}$. O meio alcalino promove a formação de cargas negativas sobre adsorbatos e substrato, além de provocar transições do tipo ordem-desordem nas conformações das cadeias de xantana e amido, favorecendo a adsorção. Íons $\mathrm{Na}^{+}$e $\mathrm{Ca}^{2+}$ são de fundamental importância nos processos de adsorção dos polissacarídeos. O provável mecanismo para adsorção de xantana e amido propilado em sílica seria aquele de "bridging", onde os cátions da solução competem com as moléculas dos polímeros por espaço na superfície da sílica e, por estarem em maior concentração que os polímeros, adsorvem e neutralizam as cargas dos sítios ativos da sílica reduzindo as forças de repulsão entre a sílica e esses polímeros. Com isso, ocorre a adsorção dos polímeros na superfície da sílica e quanto maior for o $\mathrm{pH}$ do fluido, maior a competição e a neutralização e, também, maior a adsorção.

A dessorção da camada adsorvida de fluido "drill-in" é fraca e o tipo de mecanismo de rompimento, por remoção ou deslocamento da torta adsorvida nas paredes dos poros, apresenta pouca tendência de ocorrer.

Os valores semelhantes de constantes de adsorção de xantana e amido propilado sobre $\mathrm{SiO}_{2}$ determinados em pH 6 indicam que nesta condição não há competição entre os polímeros pelo substrato.

\section{AGRADECIMENTOS}

D. F. S. Petri agradece ao CNPq pela Bolsa de Produtividade em Pesquisa e a G. da S. Gomes pela realização de experimentos de adsorção.

\section{REFERÊNCIAS}

1. Amanullah, Md.; Yu, L.; J. Petrol. Sci. Eng. 2005, 48, 199.

2. Houwen, O.; Ladva, H.; Meeten, G.; Reid, P.; Williamson, D.; Oilfield Review 1997, 9, 3 .

3. Lummus, J. L.; Azar J. J.; Drilling Fluids Optimization; A Practical Field Approach, Pennwell Books: Tulsa, Oklahoma, 1986.

4. Queiroz Neto, J. C.; Anais do III Seminário de Engenharia de Poço, Rio de Janeiro, Brasil, 1999.

5. Queiroz Neto, J. C.; Anais do SPE International Symposium and Exhibition on Formation Damage Control, Lafayette, EUA, 2002.

6. Donovan, J.P.; Jones, T. A.; Anais do SPE European Formation Damage Conference, The Hague, Holanda, 1995.

7. Rosalam, S.; England, R.; Enzyme Microb. Technol. 2006, 39, 197.

8. Navarrete, R. C.; Dearing, H. L.; Constien, V. G.; Marsaglia, K. M.; Seheult, J. M.; Rodgers, P. E.; Anais da Asia Pacific Drilling Technology Conference, Kuala Lumpur, Malasia, 2000.

9. Nasr-El-Din, H. A.; Taylor, K. C. Em Multiphase Reactor and Polymerization System Hydrodynamics; Cheremisinoff, N. P., ed.; Advances in Engineering and Fluid Mechanics Series, Gulf Publishing Co.: Houston, 1996, p. 615-668.

10. Wurzburg, O. B.; Modified Starches: Properties and Uses, CRC Press Inc.: Boca Raton, 1986.

11. Simonides, H.; Schuringa, G.; Ghalambor, A.; Anais do SPE International Symposium and Exhibition on Formation Damage Contro, Lafayette, EUA, 2002.

12. Katzbaue, R. B.; Polym. Degrad. Stabil. 1998, 59, 81

13. Davidson, E.; Stewart, S.; Anais da SPE/IADC Middle East Drilling Technology Conference, Bahrain, Emirados Árabes, 1997.

14. Knox, D.; Jiang, P.; Anais do SPE International Symposium on Oifield Chemistry, Houston, EUA, 2005.

15. Azzam, R. M. A.; Bashara, N. M.; Ellipsometry and Polarized Light, North Holland Publication: Amsterdam, 1987.

16. Gonçalves, D.; Irene, E. A.; Quim Nova 2002, 25, 794

17. Fujimoto, J.; Reis, E. A. O.; Campana Filho, S. P.; Petri, D. F. S.; Quim. Nova 2002, 25, 757

18. Edward P.; Handbook of optical constants of solids, Academic Press Inc.: Londres, 1985.

19. Brandrup, J.; Immergut, E. H.; Polymer Handbook, $2^{\text {nd }}$ ed., John Wiley \& Sons: New York, 1966.

20. Teófilo, R. F.; Ferreira, M. M. C.; Quim Nova 2006, 29, 338.

21. Suhara, T.; Fukui, H.; Yamaguchi, M.; Colloids Surf., A 1995, 101, 29.

22. Iler, R. K.; The Chemistry of Silica, Wiley \& Sons Publishers: New York, 1979.

23. Wiegand, G.; Jaworek, T.; Wegner, G.; Sackmann, E.; Langmuir 1997, 13, 3563 .

24. Atkins, P.W.; Physical Chemistry, $5^{\text {th }}$ ed., Oxford University Press: Oxford,1994.

25. Castro, L. B. R.; Petri, D. F. S.; J. Nanosci. Nanotechnol. 2005, 5, 2063.

26. Pereira, E. M. A.; Petri, D. F. S.; Carmona-Ribeiro, A.-M.; J. Phys. Chem. B 2006, 110, 10070 .

27. Tinland, B.; Rinaudo, M.; Macromolecules 1989, 22, 1863; Rinaudo, M.; Food Hydrocolloids 2001, 15, 433.

28. van de Steeg, H. G. M.; Cohen Stuart, M. A.; de Keizer, A.; Bijsterbosch, B. H.; Langmuir 1992, 8, 2538.

29. Fujimoto, J.; Petri, D. F. S.; Langmuir 2001, 17, 56.

30. Jane, J. L.; Starch/Stärke 1993, 45, 161.

31. Chiotelli, E.; Pilosio, G.; Le Meste, M.; Biopolymers 2002, 63, 41.

32. Lecourtier, J.; Lee, L. T.; Chaveteau, G.; Colloid Surf. 1990, 47, 219.

33. Jonsson, B.; Holmberg, K.; Lindman, B.; Kronberg, B.; Surfactants and Polymers in Aqueous Solution, Wiley \& Sons Publishers: Londres, 1999.

34. Siqueira, D. F.; Reiter, J.; Breiner, U.; Stadler, R.; Stamm, M.; Langmuir 1996, 12, 972

35. Oh, M.; So, J.; Yang, S.; J. Colloid Interf. Sci. 1999, 216, 320.

36. Liu, Q.; Zhang, Y.; Laskowski, J. S.; Int. J. Miner. Process. 2000, 60, 229.

37. Chiappa, L.; Mennella, A.; Lochart, P.; Burrafato, G.; J. Petrol. Sci. Eng. 1999, 24, 113 